\title{
VALUATION AND OPTIMIZATION OF INTELLECTUAL CAPITAL: A MULTICRITERIA ANALYSIS
}

\author{
Ricardo G. Dasilva 1 \\ Rua SQN, 108 Bloco C, ap 505 \\ CEP:70744-030 Brasília/DF Brasil \\ Fone: (61) 273-2425 \\ E-mail: rdasilva@cnpq.br
}

\section{Luiz Flávio Autran Monteiro Gomes ${ }^{2}$ \\ Av. Rio Branco, $108 / 5^{\circ}$ andar \\ CEP: 20040-001 Rio de Janeiro/RJ Brasil \\ Fone: (21) 3806-4053 \\ E-mail: autran@ibmecri.br}

\section{Feruccio Bilich ${ }^{3}$}

Cond. Quintas da Alvorada, 82

CEP: 71680-356 Brasília/DF Brasil

Fone: (61) 367-2272

E-mail: bilich@unb.br

${ }^{1} \mathrm{CNPq}$

CEP: 70740-901 Brasília/DF Brasil

${ }^{2}$ Faculdades Ibmec/RJ

CEP: 20040-01 Rio de Janeiro/RJ Brasil

${ }^{3}$ Universidade de Brasília - UNB

CEP: 70910-900 Brasília/DF Brasil

\section{Abstract}

The present competitive environment of the business world exerts a constant pressure on the valuation and measurement of the key organizational assets. These include Intellectual Capital, competitive intelligence and also knowledge management. This paper presents and applies a model to evaluate intangible assets employing a Multicriteria Decision Aiding method. The focus on Multicriteria Decision Aiding was adopted following a preliminary selection of multicriteria methods, opting to make use of the ELECTRE (Elimination and Choice Translating Reality) family of methods and, in particular, the multicriteria method ELECTRE TRI. This 
method makes it possible not only to evaluate and measure intangible assets such as Intellectual Capital, but also to prescribe policies for optimizing intangible assets or, in other words, how and where the organization should invest, at a minimum effort, in order to improve its market value. The conclusions of the paper lead to a vision of new possibilities for the application of the analytical methodology for the valuation of Intellectual Capital. It is worth highlighting the fact that the analysis of the valuation and optimization of intangible assets transcends the ambit of one simple area of knowledge. It is to be found in various areas of knowledge, combining methods and concepts which transcend the ambit of the decision sciences, administration, accounting, financial theory, and operational research itself, relying on a multidisciplinary vision of the organization.

Key words: Decision analysis - Intangible goods - Human resources - Management of organizations - Valuation 


\section{Introduction}

This paper presents and applies a model for evaluating intangible assets using a Multicriteria Decision Aiding method. The intangible asset specifically analyzed was Intellectual Capital. This asset is an intangible which is increasingly gaining in value as a result of the changes brought about in knowledge management. Intellectual Capital can be divided into four categories: market assets, human assets, intellectual property assets and infrastructure assets.

Edvinson and Malone (1997) describe Intellectual Capital in a metaphor, comparing an organization to a tree. The visible part represents the company structure, the financial statements and other accounting and financial documents. The other part, which, although it belongs to the same organization is to be found hidden below the surface, is made up of the more dynamic factors which support the organization. However, as a value aggregator, Intellectual Capital should principally be evaluated in high technology and service companies.

The current competitive environment for organizations exerts a constant pressure on the valorization of the intangible assets. This competitive scenario demands the valuation and measurement of assets including and principally focusing on Intellectual Capital. In the valuation and consequent measurement the market must be taken into consideration, with its occasional financial instability, as well as its possible institutional turbulence.

This being so, the central purpose of this paper is to demonstrate the suitability of multicriteria decision support methods as an operational strategy to evaluate, measure and optimize Intellectual Capital.

The focus on Multicriteria Decision Aiding was adopted following a preliminary selection of multicriteria methods, opting to make use of the ELECTRE (Elimination and Choice Translating Reality) family of methods and, in particular, the multicriteria method ELECTRE TRI (Yu and Roy, 1992).

The analysis presented fully justifies itself, as, today, the survival of organizations is characterized by uncertainties and by their valorization in the market, making it a great challenge to establish the criteria to be adopted in the decision-making process. Multicriteria methods are recommended, as they permit consideration of a diversity of processes and the participation of various actors, including decision-making under situations of uncertainty, conflicts of interest and the elicitation of judgement values. 


\section{Analytical Framework}

For a long time, wealth was associated with the possession of physical assets, which in addition were easy for accounting, being expressed in a direct form in the balance sheets and annual financial statements. However, in current society wealth derives principally and increasingly from intangible intellectual assets, or, in other words, knowledge is becoming the most valuable production factor.

The technological advances of the last two decades have determined that highly valued knowledge is that which can be applied systematically and objectively. In this way, the current "organization of knowledge" is one whose key resources are knowledge, both explicit and tacit, providing clearly observable competitive advantages which, in a general way, are truly valued in the organizations (Nonaka and Takeuchi, 1995).

One fact that has great relevance for the analysis is that knowledge is not related to the quantity of information, as it is not enough to have it or manipulate it. It is making intelligent use of it, which is indispensable. In this way, if the managers/decision makers themselves are not attentive to changes, or if they refuse to abandon the ideas which brought success to the organizations in the past, they will be seen as the greatest obstacle in confronting the competition.

For Sveiby (1997) the question of knowledge is the art of creating value from the leverage of the intangible assets of an organization. Starting from this argument, Sveiby considers intangible assets to be represented by the following elements: external structure, internal structure and the competence of the employees. In synthesis, the author considers intangible assets basically to be composed of competence, relationships and information.

Intellectual Capital is, in fact, a term used to describe organizations of knowledge which use their intangible assets as resources to secure competitive advantages. They also use other intangible assets, such as specific techniques and products, patented processes, know-how inherent to production and to the knowledge of the market, and their own competitive intelligence.

Generally speaking, there are many words to describe Intellectual Capital, such as: invention, technology, ideas, skills, processes or creativity. However, what principally characterizes it is the interaction between tacit and explicit knowledge, which, together with the company culture, places it in a sustainable position in the market. 
Increasingly, studies are showing that organizations' assets are more than the traditional domains of capital, of physical assets (property), or workforce. These materials can easily be appropriated and/or substituted inside the competition process, which does not occur with intangible assets

Thus, there is much attention focused on Intellectual Capital, for, in the environment of competitive business, ideas and innovations are currency and information about markets and clients are valorized more and more through greater investment in: 1) the development of a competent workforce which produces gains for the organization, through their knowledge, capacity for action and creativity; 2) an internal structure which includes new concepts of management, information systems, technology and use of networking, serving as support to allow the human resources cited above to develop; 3) an external structure which corresponds to the relations with the market and, principally, with clients and suppliers, in which a great investment is made in the organization's image; 4) intellectual property which corresponds to the legal mechanism for the protection of the company's assets, such as, patents, copyright, design and brands, as well as trade secrets to maintain the competitive strategy.

\section{Research Methodology}

The methodology employed in carrying out the research used the following steps: bibliographic research; definition of sample of organizations based on Intellectual Capital; development and application of the questionnaire; processing of data through the specific Multicriteria Decision Support software and analysis of the results.

From the review of the literature on Intellectual Capital, the most relevant criteria for its valuation was identified and, based on this knowledge, a questionnaire was designed to be employed in the valuation and measurement of the Intellectual Capital.

The questionnaire was applied to 30 software producing technology companies, with the questionnaires answered by the decision owners. Of these questionnaires, 19 were valid, 10 were not returned and 1 was rejected.

As Intellectual Capital is a multidimensional asset, which is difficult to reduce to a single dimension of the monetary asset type, Multicriteria Decision Support methods can be employed to capture all of its relevant and important dimensions, associating each criterion to one dimension of the problem. 
On the other hand, the ELECTRE family methods seek to eliminate dominated alternatives according to a group of weights assigned by the decision-maker to each objective of the problem called methods of outranking. They are based on the construction of outranking relationships, which incorporate the preferences established by the decision-maker in the face of the problem and the alternatives available.

When a characteristic is not completely known, as in the case of Intellectual Capital, or when there are uncertainties as to its behaviour, it is possible to obtain information based on the prior knowledge of a specialist on the subject, reflected in the value judgements. In this way, the decision-maker establishes relative weights for the criteria and makes an valuation of each alternative for each criterion. The decision-maker also establishes the limits so that the indices of agreement and disagreement can be validated. The ELECTRE TRI method (Yu and Roy, 1992) is a decision aiding instrument, known specially for dealing with problems of classification (TRI), examining the intrinsic value of each action in order to supply a recommendation which would provide an appropriate optimization for each item of the Intellectual Capital.

At the same time, a critical reading of the questionnaires was begun with the aim of finding out how this process of validating the measurable criteria could be developed. Thus, the positive aspects and possible faults were analyzed, as well as assistance sought for the definition of criteria and procedures to examine Intellectual Capital in the organizations.

The data obtained from the questionnaires was put into tables and processed by the ELECTRE TRI software, which is considered the most suitable for both the simulation and obtaining of results and for the later carrying out of sensitivity analyses of the attributes of Intellectual Capital.

It was observed that the criteria selected were those customarily found in fact finding and directly related to the subject of the study, the examination of Intellectual Capital. The criteria selected were: 1) Investment in company name/brand; 2) Valuation of financial return; 3) Client satisfaction; 4) Professional and academic background; 5) Level of interaction between sectors; 6) Dedication of the human resources to the company; 7) Monitoring of new technologies; 8) Competence management; 9) Information systems; and 10) Continued decision-making. 


\section{Application of the ELECTRE TRI Method}

With the aim of checking the applicability of the ELECTRE TRI method and taking into account the organizations to be analyzed, the methodology was tested using 5 reference actions, defined by $\mathrm{b}$ to $\mathrm{b}$ and three thresholds ( $\mathrm{q}$ - indifference; $\mathrm{p}$ - preference and $\mathrm{v}$ - veto). The application of the software to the data collected resulted in the values shown in Table 1 , supplying the reference actions for the thresholds. These actions defined six categories of classification ( $\mathrm{E}_{1}$ to $\left.\mathrm{E}_{6}\right)$.

\begin{tabular}{c|c|c|c|c|c}
\hline Threshold & \multicolumn{5}{|c}{ Reference actions } \\
\hline & $\mathrm{b}_{1}$ & $\mathrm{~b}_{2}$ & $\mathrm{~b}_{3}$ & $\mathrm{~b}_{4}$ & $\mathrm{~b}_{5}$ \\
$\mathrm{q}$ (indifference) & 0.5 & 0.5 & 1.0 & 1.0 & 1.0 \\
\hline $\mathrm{p}$ (preference) & 1.0 & 1.0 & 2.0 & 3.0 & 3.0 \\
\hline $\mathrm{v}$ (veto) & 1.5 & 2.0 & 3.0 & 4.0 & 5.0 \\
\hline
\end{tabular}

Table 1: Reference actions and their meanings

For the reference actions $\mathrm{b}$ to $\mathrm{b}_{3}$, the weights attributed to each criterion were considered constant. The six categories $\left(\mathrm{E}_{1}\right.$ to $\left.\mathrm{E}_{6}\right)$ were: $\mathrm{E}_{1}$ - Extremely efficient; $\mathrm{E}$ - Very efficient; $\mathrm{E}_{3}$ Averagely efficient; $\mathrm{E}_{4}-$ Weakly efficient; $\mathrm{E}_{5}-\mathrm{A}$ little inefficient; $\mathrm{E}_{6}-$ Very inefficient.

The organizations classified in categories below the average $\left(E_{4}\right)$ were considered inadequate for measuring Intellectual Capital. From the information previously obtained and considering the specific nature of the organizations to be evaluated, in other words, the specific importance of each criterion, it was decided to use criteria which could be applicable to more general categories of organizations.

The criteria for numbers 8 and 9 respectively, Management of Competencies and Information Systems, were substituted by the following more general criteria: Quality control of products/processes and Plan of investment in Research and Development, respectively. This substitution occurred due to the fact that the previous criteria were classified below $\mathrm{E}_{4}$. 
The criteria were all evaluated according to a numerical scale from 1 to 7 , value 1 corresponding to the wor st valuation for that criteria and value 7 , the best valuation.

In fact, ELECTRE TRI allows reference actions with differentiated values to be created for each criterion.

In the specific case of this work, it was decided to define a numerical scale, which would allow the criteria to be measured from the same reference. The comparison between the actions is processed, in this way, more in function of the valuation scale adopted than in function of the definition of the criteria for each reference action.

The level of importance, that is, the weight of each criterion, was also defined in a scale of 1 to 7 , with 1 being the weight of a criterion of very little importance and 7 the weight of a criterion of extreme importance.

The result of the five simulations is presented in Table 2. Simulation $\mathrm{b}$ represents the moment in which there are a greater number of non-conformities. In the following simulations, an attempt was made to incorporate possible improvements in the valuation of the Intellectual Capital, permitting an improvement in the performance of the company benchmark, without, however, it being necessary to obtain the maximum valuation for the criteria established.

\begin{tabular}{|c|c|c|c|c|c|c|}
\hline \multirow[b]{2}{*}{ Criteria } & \multirow[b]{2}{*}{ Weight } & \multicolumn{5}{|c|}{ Simulation } \\
\hline & & $b_{1}$ & $\mathrm{~b}_{2}$ & $b_{3}$ & $b_{4}$ & $b_{5}$ \\
\hline 1. Investment in company name/brand & 7 & 2 & 4 & 4 & 5 & 6 \\
\hline 2. Valuation of financial return & 7 & 1 & 3 & 4 & 5 & 6 \\
\hline 3. Client satisfaction & 7 & 1 & 1 & 2 & 3 & 4 \\
\hline 4. Professional and academic background & 6 & 1 & 2 & 4 & 4 & 4 \\
\hline 5. Level of interaction between sectors & 6 & 2 & 3 & 5 & 5 & 6 \\
\hline 6. Dedication of human resources & 5 & 1 & 1 & 2 & 3 & 3 \\
\hline 7. Monitoring of new technologies & 7 & 1 & 1 & 3 & 4 & 6 \\
\hline 8. Quality control products/processes & 5 & 1 & 1 & 1 & 2 & 4 \\
\hline 9. Investment plan in R \& D & 5 & 1 & 1 & 1 & 2 & 4 \\
\hline 10. Continued decision-making & 6 & 2 & 2 & 2 & 2 & 4 \\
\hline
\end{tabular}

Table 2: Application of the ELECTRE TRI method 
Using the values of the reference actions and the adoption of the thresholds, the ELECTRE TRI method was applied, considering the cut-off level $\lambda=0.67$. By employing the method, and using the procedure of optimistic assignment, the classification of the organization was defined.

Based on the result, it was concluded that the organization would only manage to attain its maximum Intellectual Capital if the performance of the valorization was equal or superior to that presented in Simulation $b_{4}$.

The test carried out showed that, using the HECTRE TRI method, it was possible to check, in an explicit manner, whether the valuation performance and the asset where the company should invest would make an improvement in its market value.

If a new criterion were considered, a classification would be obtained in the same way which would also vary from 1 to 7 .

It is essential to stress that the initial proposal of this methodology incorporated the reference actions and the categories of the companies being researched, as well as the criteria, weights and thresholds previously established.

The performance of the companies according to each of the criteria was evaluated by the authors adopting two scales of measurement: one of percentages varying from 0 to $100 \%$ and the other a linguistic valuation with seven gradations.

In the valuation with the ELECTRE TRI method, the companies were allocated in a previously defined standard, which was composed of 5 reference actions and 6 differentiated categories, according to the performance of the Intellectual Capital. The valuation was structured in three stages and it was proposed to analyze the questionnaires of the companies which use Intellectual Capital as a means to add market value and improve competitiveness. The optimization analysis was performed from the sensitivity analysis carried out using the ELECTRE TRI method, considering the companies with a cut-off level $\lambda$ equal to 0.67 .

In the first stage - Classification - the results obtained in the questionnaires were discussed and 2 companies, denominated $\mathrm{X}$ and $\mathrm{Y}$, classified from among those analyzed

The second stage - Sensitivity Analysis - presented in two types of tests, was designed to evaluate the stability of the results obtained in the face of a change in the thresholds of the cut-off levels and the weights. 
The third stage - Optimization - sought to check the sequence of improvements necessary for the companies to move up an increment in their classifications.

\section{Valuation and Measurement}

When using the ELECTRE TRI method to evaluate Intellectual Capital, the decisionmaker is responsible for the consideration of criteria, cut-off levels of thresholds and weights. Even though these parameters are, in the beginning, difficult to interpret and evaluate, the decision makers are in the best position to carry out this valuation as they have a global understanding of the implications of these values in terms of adding market value.

The application of the ELECTRE TRI software approaches the problem of decisionmaking, substituting the attributes by the indirect selection of the parameters of the model. The values of the parameters are inferred from an analysis of the attributes.

The ELECTRE TRI model implements this analysis in such a way that the least cognitive effort is required of the decision-maker. The choice of parameters is made indirectly, that is, using information supplied by the decision-maker, making use of a scale of attribute values.

For the purpose of analysing the data, tests were carried out, with the aim of evaluating the stability of the results obtained, according to changes in the parameters of the ELECTRE TRI method. A synthesis is presented in Table 3 . 


\begin{tabular}{|c|c|c|c|c|c|}
\hline \multirow[t]{2}{*}{ Threshold } & \multirow{2}{*}{$\begin{array}{l}\lambda \\
\text { (a) }\end{array}$} & \multicolumn{2}{|c|}{ Test L $L_{1}(b)(c)$} & \multicolumn{2}{|c|}{ Test $\mathrm{L}_{2}(\mathrm{~b})(\mathrm{c})$} \\
\hline & & $\begin{array}{c}\text { Company } \\
\text { X }\end{array}$ & $\begin{array}{c}\text { Company } \\
\mathrm{Y}\end{array}$ & $\begin{array}{c}\text { Company } \\
\mathrm{X}\end{array}$ & $\begin{array}{c}\text { Company } \\
\mathrm{Y}\end{array}$ \\
\hline \multirow[t]{5}{*}{ Type A } & 0.5 & $\mathrm{C}_{4}$ & $\mathrm{C}_{1} \mathrm{C}_{2}$ & $\mathrm{C}_{4}$ & $\mathrm{C}_{1} \mathrm{C}_{2}$ \\
\hline & 0.7 & $\mathrm{C}_{2} \mathrm{C}_{3}$ & $\mathrm{C}_{1} \mathrm{C}_{2}$ & $\mathrm{C}_{4}$ & $\mathrm{C}_{1} \mathrm{C}_{2}$ \\
\hline & 0.8 & $\mathrm{C}_{2} \mathrm{C}_{4}$ & $\mathrm{C}_{1} \mathrm{C}_{2}$ & $\mathrm{C}_{2} \mathrm{C}_{4}$ & $\mathrm{C}_{1} \mathrm{C}_{2}$ \\
\hline & 0.95 & $\mathrm{C}_{2} \mathrm{C}_{4}$ & $\mathrm{C}_{1} \mathrm{C}_{3}$ & $\mathrm{C}_{2} \mathrm{C}_{4}$ & $\mathrm{C}_{1} \mathrm{C}_{3}$ \\
\hline & 1.0 & $\mathrm{C}_{2} \mathrm{C}_{5}$ & $\mathrm{C}_{1} \mathrm{C}_{3}$ & $\mathrm{C}_{2} \mathrm{C}_{5}$ & $\mathrm{C}_{1} \mathrm{C}_{3}$ \\
\hline \multirow[t]{5}{*}{ Type B } & 0.5 & $\mathrm{C}_{3} \mathrm{C}_{4}$ & $\mathrm{C}_{1} \mathrm{C}_{2}$ & $\mathrm{C}_{3} \mathrm{C}_{4}$ & $\mathrm{C}_{1} \mathrm{C}_{2}$ \\
\hline & 0.7 & $\mathrm{C}_{2} \mathrm{C}_{4}$ & $\mathrm{C}_{1} \mathrm{C}_{2}$ & $\mathrm{C}_{3} \mathrm{C}_{4}$ & $\mathrm{C}_{1} \mathrm{C}_{2}$ \\
\hline & 0.8 & $\mathrm{C}_{2} \mathrm{C}_{4}$ & $\mathrm{C}_{1} \mathrm{C}_{2}$ & $\mathrm{C}_{2} \mathrm{C}_{4}$ & $\mathrm{C}_{1} \mathrm{C}_{2}$ \\
\hline & 0.9 & $\mathrm{C}_{2} \mathrm{C}_{4}$ & $\mathrm{C}_{1} \mathrm{C}_{3}$ & $\mathrm{C}_{2} \mathrm{C}_{4}$ & $\mathrm{C}_{1} \mathrm{C}_{3}$ \\
\hline & 1.0 & $\mathrm{C}_{2} \mathrm{C}_{5}$ & $\mathrm{C}_{1} \mathrm{C}_{3}$ & $\mathrm{C}_{2} \mathrm{C}_{5}$ & $\mathrm{C}_{1} \mathrm{C}_{3}$ \\
\hline
\end{tabular}

Table 3: Results from valuations for changes in $\lambda$ as well as in the thresholds. Notes: (a) the cut-off levels $(\lambda)$ varied from 0.5 to 1.00; (b) a minimum performance of $\mathrm{C}_{4}$ was established for consideration for valuation; (c) the categories varied from $\mathrm{C}_{1}$ to $\mathrm{C}_{6}$.

In the first test, $\mathrm{L}_{1}$, the parameters of the thresholds were analyzed and two different groups of thresholds adopted (Type A and Type B), relating to the two groups of criteria, with values of cut-off levels $(\lambda)$ variable from 0.5 to 1.0 , with increments of 0.05 . In Table $3, C_{1}, C_{2}$, $\mathrm{C}_{3}, \mathrm{C}_{4}, \mathrm{C}_{5}$, and $\mathrm{C}_{6}$ are categories; where $\mathrm{C}_{1}$ is the weakest category and $C_{6}$ is the strongest category. Combinations of the type $\mathrm{C}_{1} \mathrm{C}_{2}$ indicate that the valuation fell between category $\mathrm{C}_{1}$ and category $\mathrm{C}_{2}$. In other words, the valuation is better than category $\mathrm{C}_{1}$, but has not yet reached $\mathrm{C}_{2}$. As the categories are in a n-dimensional space which, in this case, implies 6 dimensions, an evolution from category $C_{1}$ to category $C_{3}\left(C_{1} C_{3}\right)$ can take place without passing through category $\mathrm{C}_{2}$.

It can be observed that, in general, the values of the cut-off levels presented are those where modifications were observed, while the intermediary values, which do not appear in Table 3 , correspond to no alteration in the valuation. 
For company Y, considering the two types of threshold (A and B) and the two tests (Test $L_{1}$ and Test $\mathrm{L}_{2}$ ), the classification obtained was always constant and equal to $\mathrm{C}_{1} \mathrm{C}_{2}$, for $\lambda \leq 0.8$. For values of $\lambda \geq 0.95$ and threshold type $A$, an increment in the optimistic valuation was observed, in relation to the previous result, from $C_{1} C_{2}$ to $C_{1} C_{3}$. For thresholds of type $B$, the same occurred for $\lambda \geq 0.90$.

For company Y, considering a cut-off level between $0.8 \leq \lambda \leq 0.9$ and using the type A threshold, the valuations remained unaltered and equal to $C_{1} C_{2}$. For $\lambda \geq 0.95$ an increment in the classification was observed to $C_{1} C_{3}$, contrasting with the valuation $C_{1} C_{2}$ for $\lambda<0.95$.

Therefore company $\mathrm{Y}$ had uniformity in the results, considering two groups of thresholds, when $\lambda<0.8$. However, increments in the classification were observed (optimistic valuation) for values of $\lambda \geq 0.95$ and $\lambda \geq 0.90$ and in the thresholds of types $A$ and $B$, to, respectively, $C_{1} C_{3}$, in both cases.

The result observed is, possibly, a reflection of the values of veto lower than the cut-off levels. It can be observed that, for the same group of thresholds, the behavior of the valuations was uniform, considering different values of cut-off levels $(\lambda)$.

For company $\mathrm{X}$, considering the valuations for the two types of thresholds, Type A and Type $\mathrm{B}$, and the two tests (Test $\mathrm{L}_{1}$ and Test $\mathrm{L}_{2}$ ), uniformity in the valuation equal to $\mathrm{C}_{2} \mathrm{C}_{4}$ was observed for $0.8 \leq \lambda \leq 0.95$. When the cut-off level reached $(\lambda=1.0)$, the category valuation passed from $\mathrm{C}_{2} \mathrm{C}_{4}$ to $\mathrm{C}_{2} \mathrm{C}_{5}$.

For company $\mathrm{X}$ considering $0.5 \leq \lambda \leq 0.7$, with threshold type $\mathrm{A}$, the valuations were always equal to $\mathrm{C}_{4}$. For thresholds of type $\mathrm{B}$, and the same interval of $\lambda$, the valuation was always equal to $\mathrm{C}_{3} \mathrm{C}_{4}$.

The results obtained for company $\mathrm{X}$, with $0.7 \leq \lambda \leq 0.8$ and comparing them with values of $\lambda<0.7$, indicate that this company underwent a drop in its valuation, passing from $C_{4}$ to $C_{2} C_{3}$, in its classification.

The valuations of company $\mathrm{X}$, for $(\lambda>0.90)$, in the test of thresholds (Type B), as well as in the tests (Test $\mathrm{L}_{1}$ and Test $\mathrm{L}_{2}$ ) underwent a change in the classification of the company (rising valuation) from $\mathrm{C}_{2} \mathrm{C}_{4}$ to $\mathrm{C}_{2} \mathrm{C}_{5}$. 
Therefore, coherence was observed in the values of the differences between the two companies, as the number of non-conformities with the optimum, observed in company $\mathrm{Y}$, is considerably greater than in company $\mathrm{X}$.

It can be observed that the result of company $\mathrm{Y}$ was possibly a reflection of the zero scoring in more than one criterion. In this way, no significant improvement was observed related to the change in the thresholds. It was very different in the case of company $\mathrm{X}$, where improvements for different groups of thresholds were observed, due to its better performance in all the criteria, compared with company Y.

\section{Optimization of Intellectual Capital}

Optimization of Intellectual Capital through the use of the ELECTRE TRI Multicriteria Decision Aiding method seeks to determine the components of a vector of global performance of Intellectual Capital. In a diffrent way from a single criterion optimization, the solution for the problem is, therefore, an efficient group of optimizations. Each of these valuations is the best in the sense that no improvement can be made in a component of the global performance vector without there being a dvaluation in at least one of the remaining criteria. Therefore, among the optimizations proposed, the decision-maker will choose the solution which is judged the most satisfactory or Pareto-optimum.

Next, the identification of the sequence of improvements to be carried out in each company was sought. Starting from the valuation of companies $\mathrm{X}$ and $\mathrm{Y}$, respectively $\mathrm{C}_{4}$ and $\mathrm{C}_{2}$ (before optimization), the actions which would be necessary to optimize their classifications were simulated.

In this case, category $\mathrm{C}_{5}$ was established for company $\mathrm{X}$ and $\mathrm{C}_{4}$ for company $\mathrm{Y}$, as optima obtainable with the minimum possible effort. In this way, company $\mathrm{Y}$ would also obtain a good result for Intellectual Capital. Table 4 presents the simulations for optimizing the Intellectual Capital of company X.

In total, 20 simulations (S) were carried out for company X and 34 for company Y. These simulations took into consideration investment in the diverse criteria, which were put into a hierarchy arranged in an index of increasing difficulty, varying from 1 to 5 . In this way, an optimization in the valuation of the intangible asset, in this case Intellectual Capital, was obtained. 
The index of difficulty was used to place the investments needed to achieve the optimum into a hierarchy. Simulation $\mathrm{S}_{7}$ resulted in an index of difficulty of 20 for company $\mathrm{X}$ and, simulation $\mathrm{S}_{9}$, resulted in an index of difficulty of 34 for company $\mathrm{Y}$. These indices were the smallest necessary for the companies to reach their respective optima of Intellectual Capital.

In the case of company $\mathrm{Y}$, the simulations showed that it could reach category $\mathrm{C}_{4}$ if there were an increase in investments in the criteria 2, 3 and 6.

For company $\mathrm{X}$ to reach category $\mathrm{C}_{5}$, it would only be necessary to perform the implementation in criterion 6 related to the dedication of the human resources. In other words, it would be necessary to re-dimension its policy of empowering its internal collaborators through a better positioning of the management of knowledge, both tacit and explicit.

The ELECTRE TRI method of Multicriteria Decision Aiding thus showed itself to be efficient in the process of valuation, measurement and optimization of Intellectual Capital.

\begin{tabular}{l|c|c|c|c|cc|c|c|c|c|c|c}
\hline \multicolumn{2}{c|}{ Criteria } & \multicolumn{10}{c}{ Simulations } \\
\hline \multicolumn{2}{l|}{$\begin{array}{c}\text { Weight } \\
\text { s }\end{array}$} & $\mathrm{S}_{1}$ & $\mathrm{~S}_{2}$ & $\mathrm{~S}_{3}$ & $\mathrm{~S}_{4}$ & $\mathrm{~S}_{5}$ & $\mathrm{~S}_{6}$ & $\mathrm{~S}_{7}$ & $\mathrm{~S}_{8}$ & $\mathrm{~S}_{9}$ & $\mathrm{~S}_{10}$ \\
\hline 2 & Financial Return & 3 & 50 & 50 & 50 & 50 & 50 & 50 & 50 & 50 & 50 & 50 \\
\hline 3 & Client Satisfaction & 2.5 & 90 & 90 & 90 & 90 & 90 & 90 & 90 & 100 & 100 & 100 \\
\hline 4 & $\begin{array}{l}\text { Professional and } \\
\text { academic background }\end{array}$ & 2.5 & 50 & 50 & 50 & 50 & 70 & 70 & 70 & 70 & 70 & 70 \\
\hline 5 & Interaction of sectors & 2.5 & 50 & 50 & 50 & 50 & 50 & 50 & 50 & 50 & 50 & 50 \\
\hline 6 & $\begin{array}{l}\text { Dedication of human } \\
\text { resources }\end{array}$ & 3 & 25 & 30 & 30 & 25 & 25 & 30 & 50 & 50 & 50 & 50 \\
\hline 7 & Monitoring S \&T & 3 & 50 & 50 & 70 & 70 & 70 & 70 & 70 & 70 & 70 & 70 \\
\hline 8 & Investment in R\&D & 3 & 50 & 50 & 50 & 50 & 50 & 50 & 50 & 50 & 50 & 50 \\
\hline 9 & Other actions & 2 & 50 & 50 & 50 & 50 & 50 & 50 & 50 & 50 & 90 & 100 \\
\hline Result of ELECTRE & & $\mathrm{C}_{4}$ & $\mathrm{C}_{4}$ & $\mathrm{C}_{4}$ & $\mathrm{C}_{4}$ & $\mathrm{C}_{4}$ & $\mathrm{C}_{4}$ & $\mathrm{C}_{4}$ & $\mathrm{C}_{4}$ & $\mathrm{C}_{4}$ & $\mathrm{C}_{4}$ \\
\hline
\end{tabular}

Continuation:

\begin{tabular}{|c|c|c|c|c|c|c|c|c|c|c|c|}
\hline \multicolumn{2}{|r|}{ Criteria } & \multicolumn{10}{|c|}{ Simulations } \\
\hline & & $\mathrm{S}_{11}$ & $\mathrm{~S}_{12}$ & $\mathrm{~S}_{13}$ & $\overline{\mathrm{S}_{14}}$ & $\mathrm{~S}_{15}$ & $\mathrm{~S}_{16}$ & $\mathbf{S}_{17}$ & $S_{18}$ & $\mathrm{~S}_{19}$ & $\mathrm{~S}_{20}$ \\
\hline 2 & Financial Return & 50 & 90 & 90 & 90 & 90 & 90 & 90 & 70 & 70 & 90 \\
\hline 3 & Client Satisfaction & 90 & 75 & 90 & 100 & 90 & 90 & 75 & 90 & 90 & 75 \\
\hline 4 & $\begin{array}{l}\text { Professional and } \\
\text { academic background }\end{array}$ & 70 & 50 & 70 & 70 & 70 & 50 & 70 & 50 & 70 & 50 \\
\hline 5 & Interaction of sectors & 50 & 50 & 50 & 50 & 50 & 50 & 50 & 50 & 50 & 50 \\
\hline 6 & $\begin{array}{l}\text { Dedication of human } \\
\text { resources }\end{array}$ & 50 & 50 & 50 & 50 & 50 & 50 & 50 & 50 & 50 & 50 \\
\hline 7 & Monitoring S \& $\mathrm{T}$ & 70 & 70 & 70 & 70 & 70 & 70 & 70 & 70 & 70 & 70 \\
\hline 8 & Investment in R\&D & 50 & 70 & 70 & 70 & 50 & 70 & 70 & 70 & 70 & 70 \\
\hline
\end{tabular}




\begin{tabular}{c|l|c|c|c|cc|c|c|c|c|c|c}
\hline 9 & Other actions & & 90 & 50 & 50 & 100 & 50 & 50 & $\mathbf{5 0}$ & 90 & 90 & 90 \\
\hline Result of ELECTRE & & $\mathrm{C}_{4}$ & $\mathrm{C}_{4}$ & $\mathrm{C}_{5}$ & $\mathrm{C}_{5}$ & $\mathrm{C}_{4}$ & $\mathrm{C}_{4}$ & $\mathbf{C}_{5}$ & $\mathrm{C}_{5}$ & $\mathrm{C}_{5}$ & $\mathrm{C}_{5}$ \\
\hline \multicolumn{2}{c|}{ Index of difficulty } & & & & 21 & 33 & & & $\mathbf{2 0}$ & 22 & 24 & 21 \\
\hline
\end{tabular}

Table 4: Simulations for optimizing company X. Note: The simulation chosen, $\mathrm{S} 17$, was that which presented the smallest sum of indices of difficulty.

\section{Conclusions}

The research related in this paper proved the pertinence of the applicability of multicriteria methods in the valuation and measurement of intangible assets and, in particular, Intellectual Capital, combining the knowledge described and used by the managers/decision makers and the monitoring of the organizational system, the combination of which leads to a much better management of intangible assets.

The research demonstrated, in fact, that if the organizations used Multicriteria Decision Support methods to create indicators as in the model, they could manage the Intellectual Capital of the organization effectively and efficiently in the frequently turbulent environment of the globalized world.

The ELECTRE TRI method showed itself to be adapted to the question of valuation of Intellectual Capital, as it allowed not only the comparisons of previously defined standards but also the incorporation of a large number of variables in the valuation process. In this way, the method represented, for the context of this research, a process of interactive inference, of clustering and disaggregation of parameters, considering the variations of weights and thresholds in the sensitivity analysis and the criteria adopted by the decision-maker. These, in turn, can be validated or not by the organizations for the definition of a program of optimization aimed at competitive advantage, as they re-evaluate, in a dynamic way, all of the criteria.

Based on the sensitivity analysis, carried out using changes in weights and thresholds, practically no variation in the result was observed, which denotes the robustness of the method.

Using the ELECTRE TRI method it was also possible to check if the performance of each intangible asset was considered satisfactory, in this case, obtaining a result equal to or above the 
average, as well as to check where the company should invest, with the minimum effort, to improve its market value.

The conclusions of the research consequently permit a vision of new possibilities for the application of the analytical methodology for the valuation of Intellectual Capital. It is worth highlighting the fact that the analysis of the valuation and optimization of intangible assets transcends the ambit of one simple area of knowledge. It is to be found in various areas of knowledge, combining methods and concepts which transcend the ambit of the decision sciences, administration, accounting, financial theory, and operational research itself. The theoretical studies of the measurement of Intellectual Capital of organizations depend, therefore, on a multidisciplinary vision of the organization.

\section{References}

Edvinson, L. and Malone, N. S.: Intellectual Capital: realizing your company's true value by finding its hidden brainpower. New York, HarperCollins, 1997.

Nonaka, I. and Takeuchi, H.: The Knowledge-Creating Company: How Japanese Companies Create the Dynamics of Innovation. New York, Oxford Press, 1995.

Sveiby, K.E.: The New Organizational Wealth. San Francisco, Berret-Koehler Publishers Inc., 1997.

Yu, W. and Roy, B.: ELECTRE TRI - Aspects Méthodologiques et Manuel d'Utilisation. Cahier du Lamsade, Document nº 74. Paris: Université de Paris Dauphine, 1992. 